\title{
Improving large-scale biomass and total alkaloid production of Dendrobium nobile Lindl. using a temporary immersion bioreactor system and MeJA elicitation
}

\author{
Benhou Zhang, Zhitao Niu, Chao Li, Zhenyu Hou, Qingyun Xue, Wei Liu and Xiaoyu Ding * (D)
}

\begin{abstract}
Background: Dendrobium nobile Lindl. is an important pharmacopeial plant with medicinal and ornamental value. This study sought to provide a technical means for the large-scale production of total alkaloid in D. nobile. Seedlings were cultured in vitro using a temporary immersion bioreactor system (TIBS). The four tested immersion frequencies (min/h; 5/2,5/4,5/6, and 5/8) influenced the production of biomass and total alkaloid content. In addition, to compare the effects of different concentrations of the phytohormone methyl jasmonate (MeJA) and treatment time on biomass and total alkaloid accumulation, MeJA was added to the TIBS medium after 50 days. Finally, total alkaloid production in semi-solid system (SSS), TIBS, and TIBS combined with the MeJA system (TIBS-MeJA) were compared.
\end{abstract}

Results: The best immersion frequency was found to be $5 / 6$ (5 min every $6 \mathrm{~h}$ ), which ensured appropriate levels of biomass and total alkaloid content in plantlets. The alkaloid content and production level of seedlings were the highest after treatment with $10 \mu \mathrm{M}$ MeJA separately for 20 and 30 days using TIBS. The maximum content $(7.41 \mathrm{mg} / \mathrm{g} \mathrm{DW}$ ) and production level (361.24 mg/L) of total alkaloid on use of TIBS-MeJA were 2.32- and 4.69-fold, respectively, higher in terms of content, and 2.07- and 10.49-fold, respectively, higher in terms of production level than those on using of TIBS (3.20 mg/g DW, $174.34 \mathrm{mg} / \mathrm{L})$ and SSS (1.58 mg/g DW, $34.44 \mathrm{mg} / \mathrm{L})$.

Conclusions: Our results show TIBS-MeJA is suitable for large-scale production of total alkaloid in in vitro seedlings. Therefore, this study provides a technical means for the large-scale production of total alkaloid in D. nobile.

Keywords: Dendrobium nobile Lindl., Temporary immersion bioreactor system, Immersion frequency, MeJA, Bioactive compound

\section{Introduction}

Dendrobium, which comprises approximately $1200-1500$ species, is one of the largest genera in the family Orchidaceae, and there are approximately 80 species within the genus Dendrobium in China [1]. Dendrobium nobile Lindl is one of the most widespread species within the genus and is an important herb that has many medically

*Correspondence: dingxynjj@163.com

College of Life Sciences, Nanjing Normal University, Nanjing 210023, China important secondary metabolites, including alkaloids, flavonoids, and bioactive polysaccharides $[2,3]$. In the ancient Chinese medical book Compendium of Materia Medica, $D$. nobile is described as "the strong body." Over the past few decades, $D$. nobile has been collected in large quantities because of its high medicinal and ornamental values, resulting in the species becoming increasingly scarce, and active preservation orders have been implemented in several counties. To solve the shortage of $D$. nobile, many researchers are leaning on tissue culture seedlings instead of wild plants [4-6]. However, most of original author(s) and the source, provide a link to the Creative Commons licence, and indicate if changes were made. The images or other third party material in this article are included in the article's Creative Commons licence, unless indicated otherwise in a credit line to the material. If material is not included in the article's Creative Commons licence and your intended use is not permitted by statutory regulation or exceeds the permitted use, you will need to obtain permission directly from the copyright holder. To view a copy of this licence, visit http://creativecommons.org/licenses/by/4.0/. The Creative Commons Public Domain Dedication waiver (http://creativecommons.org/publicdomain/zero/1.0/) applies to the data made available in this article, unless otherwise stated in a credit line to the data. 
them use a semi-solid system (SSS) with narrow culture space and no effective exchange of gas inside and outside the container.

Alkaloids with complex chemical structures consist of pyrrole, indolizidine, terpenoid alkaloids, amine alkaloids, indole, quinazoline, and others are the most common active compounds in D. nobile and are found in all parts of the plant [7]. Modern pharmacology studies have shown that alkaloids can relieve pain, have antipyretic effects, reduce heart rate and blood pressure, slow down respiration, and alleviate barbiturate poisoning $[8$, 9]. Furthermore, alkaloids have numerous therapeutic activities, including hypoglycemic, anti-cataract, antitumor, anti-cell withering, and antioxidant activities; they have also been shown to be effective in treatment of Alzheimer's disease $[10,11]$. However, $D$. nobile alkaloids are mainly obtained from three-year-old plants, which are not only expensive because of their long culture duration but also require a lot of space [12].

Plant tissue culture technology is a rapid and mass propagation method for medicinal plants, and has the potential to increase the yield of secondary metabolites [13]. However, diverse culture systems influenced the propagation of plants and production efficiency of bioactive compounds [14-16]. At present, temporary immersion bioreactor system (TIBS) shows a better performance in plant biomass and bioactive compounds accumulation, especially in officinal plants [17-20]. TIBS is a liquid culture method that allows the explants to contact the medium intermittently, thus renewing the atmosphere and supplying nutrients to meet the growth of plants [21]. This semi-automatic micropropagation system is considered to be an effective method to reduce production costs and labor to a greater degree as compared with those of traditional culture methods, such as semi-solid system (SSS) [22].

Many studies have confirmed that the phytohormone methyl jasmonate (MeJA) can enhance the biosynthesis of secondary metabolites in officinal plants [23-25]. MeJA, as an elicitor, plays an important role in the signal transduction of alkaloids biosynthesis and has been reported to promote the accumulation of metabolites in Dendrobium plants [26-29]. In the present study, TIBS and MeJA were used to promote biomass and alkaloid accumulation in $D$. nobile seedlings.

\section{Results}

Effect of immersion frequency on plantlet biomass and total alkaloid during TIBS culture

In this study, four different immersion frequencies $(5 / 2$, $5 / 4,5 / 6$, and $5 / 8$ ) were designed using TIBS culture, and a traditional SSS culture was used as a control. After 80 days of growth in the TIBS culture, there were significant differences in the morphology of seedlings under different immersion frequencies, especially under $5 / 2$, and the plantlets were dwarfed and crowded in the tank. The best plantlet morphology was found at an immersion frequency of $5 / 6$, where the plants were taller and the roots showed superior morphology; the second best immersion frequency was $5 / 8$, followed by $5 / 4$, but the two were not obvious (Fig. 1). Figure 2a shows the biomass of seedlings cultured in the reactor for $80 \mathrm{~d}$ under
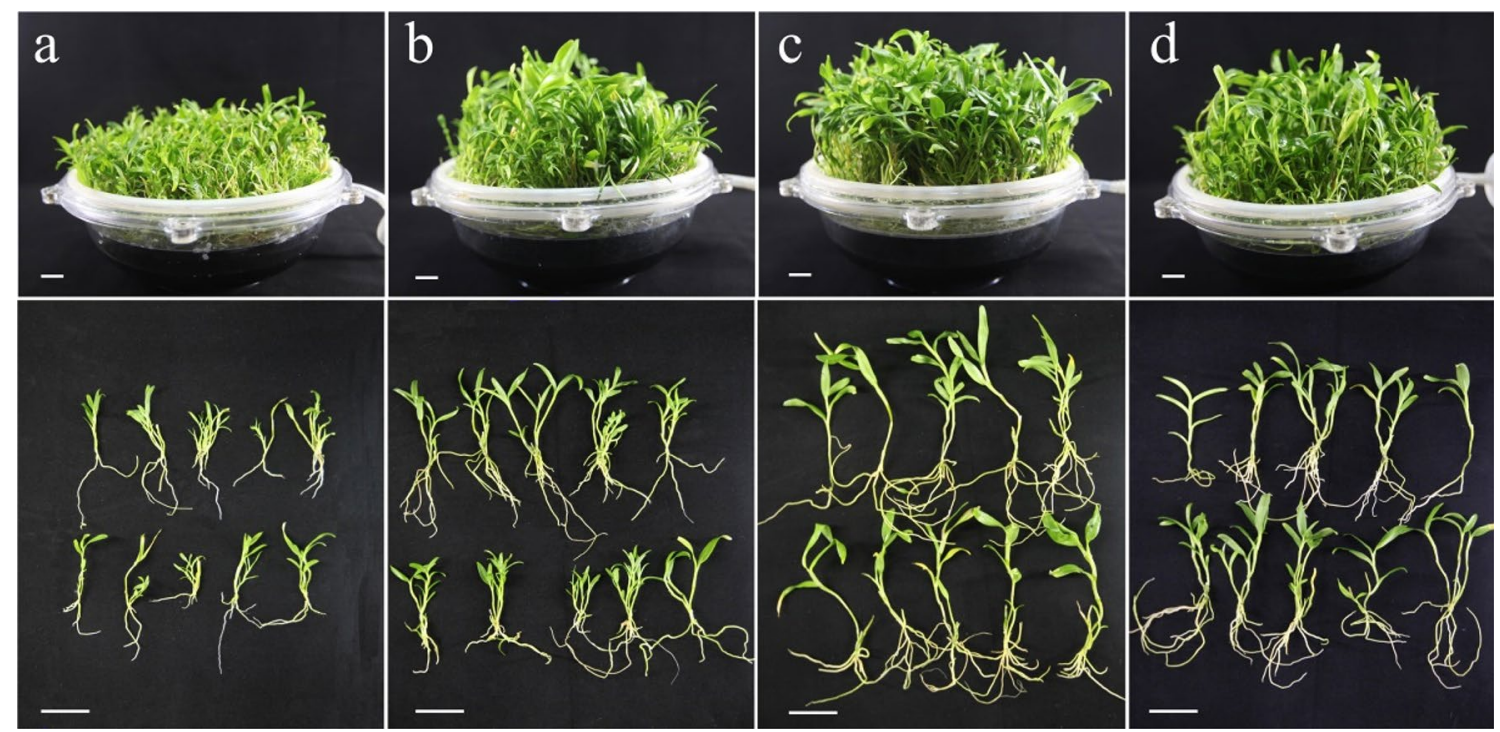

Fig. 1 Effect of immersion frequency in TIBS on growth of D. nobile for 80 days. A-d temporary immersion for 5 min every 2 h, every 4 h, every $6 \mathrm{~h}$, and every $8 \mathrm{~h}$ respectively. Scale bar $=2 \mathrm{~cm}$ 

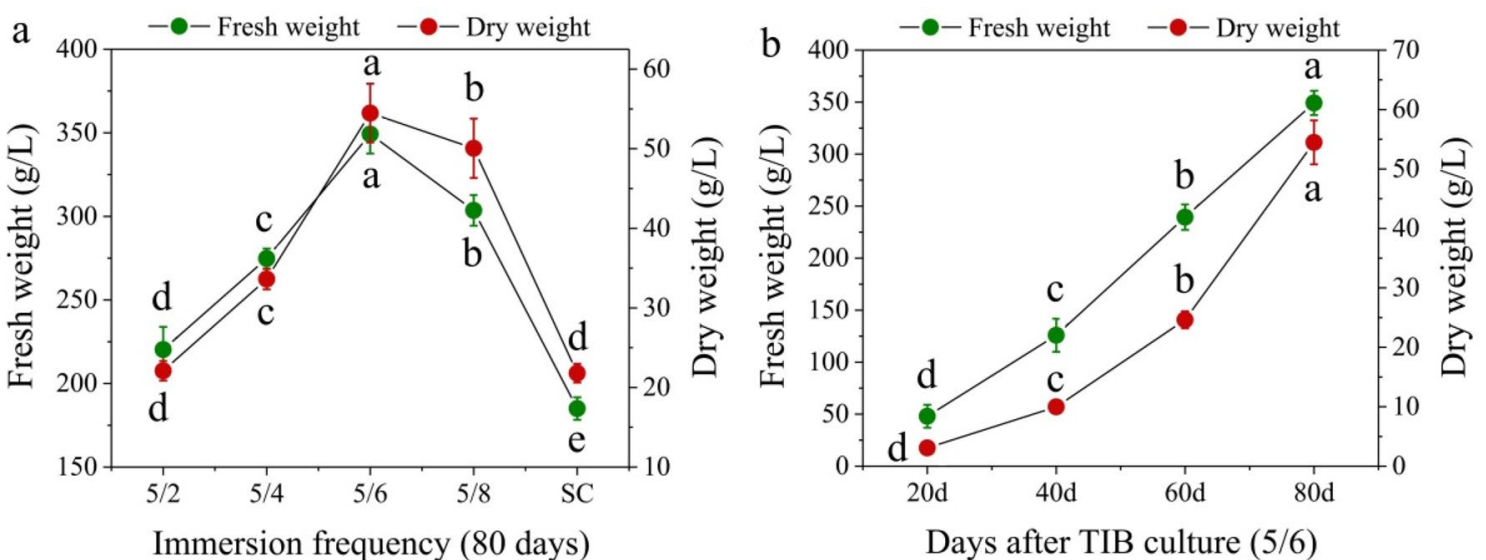

Fig. 2 a Effect of immersion frequency on biomass accumulation of D. nobile after 80 days of TIBS culture. $\mathbf{b}$ Effect of culture time on biomass accumulation of $D$. nobile at an immersion frequency of 5 min every $6 \mathrm{~h}$ of TIBS culture. Data represents the mean \pm standard error of three replicates. Bars followed by a different letter denote significant statistical differences (Tukey, $\mathrm{P} \leq 0.05$ )

different immersion frequencies. The maximum values of fresh weight $(349.23 \mathrm{~g} / \mathrm{L})$ and dry weight $(54.48 \mathrm{~g} / \mathrm{L})$ appeared in the immersion frequency of $5 / 6$. For these parameters, the second-best immersion frequency was $5 / 8$, followed by $5 / 4$ and $5 / 2$. When the immersion frequency was fixed at $5 / 6$, the fresh weight and dry weight of the seedlings in the TIBS tank increased with increasing culture time (Fig. 2b).

Figure 3 shows the effects of immersion frequency and culture duration on the total alkaloid content and production level of plantlets using TIBS culture. The highest total alkaloid content was found at an immersion frequency of $5 / 6$ for all culture durations. The total alkaloid production level of the immersion frequency $5 / 8$ was slightly higher than $5 / 6$ after 20 days of cultivation, but the highest production level was observed at an immersion frequency of $5 / 6$ for other culture durations. Moreover, the total alkaloid content and production level obtained using TIBS culture were significantly higher than those obtained using the traditional SSS culture for all culture durations. As seen in Fig. 3, the highest total alkaloid content $(3.20 \mathrm{mg} / \mathrm{g} \mathrm{DW})$ and production level $(174.44 \mathrm{mg} / \mathrm{L})$ appeared at an immersion frequency of $5 / 6$ after 80 days of cultivation.

\section{Effect of MeJA concentration during TIBS culture}

In this study, different concentrations of MeJA were added to the liquid medium after the plantlets were cultured in TIBS for 50 days. After 30 days of induction culture, different concentrations of MeJA were shown to have significant effects on the growth and proliferation of D. nobile plantlets (Fig. 4). Treatment with MeJA resulted in the necrosis of some plantlets, especially at $20 \mu \mathrm{M} \mathrm{MeJA}$, where almost half of the plantlets were necrotic. Furthermore, from the perspective of individual plants, as the concentration of MeJA increased, plantlets became shorter, with worse root growth, and a small number of plantlets became yellow. The control group without MeJA did not show necrosis and exhibited the best growth, including the roots. Figure 5 shows the fresh and dry weights of seedlings treated with different concentrations of MeJA for 30 days (Fig. 5a) and $10 \mu \mathrm{M}$ MeJA for different times (Fig. 5b) cultured using TIBS. With MeJA concentrations increasing from 0 to $20 \mu \mathrm{M}$ (interval of $5 \mu \mathrm{M}$ ), the fresh weight of plantlets decreased gradually. However, the maximum dry weight was obtained at $10 \mu \mathrm{M}$ MeJA, which was $6.79 \mathrm{~g} / \mathrm{L}$ higher than the control group (0 $\mu \mathrm{M}$ MeJA) (Fig. 5a).

Bioactive compound accumulation in D. nobile plantlets cultured using TIBS was significantly affected by MeJA treatment. The total alkaloid content and production level in the MeJA treatment groups were markedly lower than those in the control group after 10 days of MeJA treatment. But, the total alkaloid content and production level were significantly higher than other treatment groups and control group after 20 and 30 days of MeJA treatment in the $10 \mu \mathrm{M}$ MeJA treatment group, and the maximum content $(7.41 \mathrm{mg} / \mathrm{g}$ DW) and production level $(361.24 \mathrm{mg} / \mathrm{L})$ were observed after 20 and 30 days of MeJA treatment, respectively. However, when the MeJA concentration increased to $20 \mu \mathrm{M}$, the total alkaloid content was lower than other treated groups after 10 and 30 days of MeJA treatment, which were $67.62 \%$ and $83.65 \%$ of the control group, and the production level was lower than other treated groups after 20 and 30 days of MeJA treatment, which were $97.66 \%$ and $79.94 \%$ of the control group (Fig. 6). 


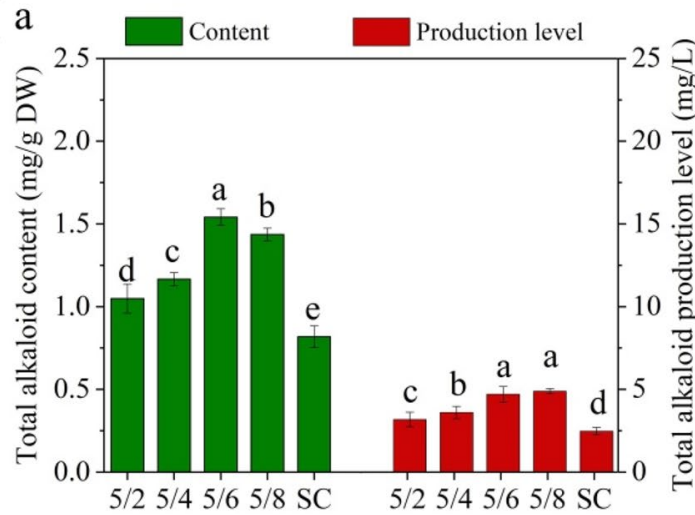

Immersion frequency

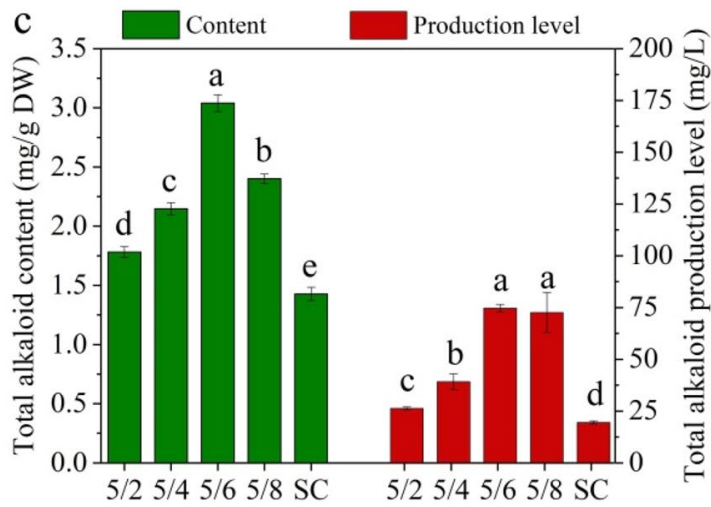

Immersion frequency

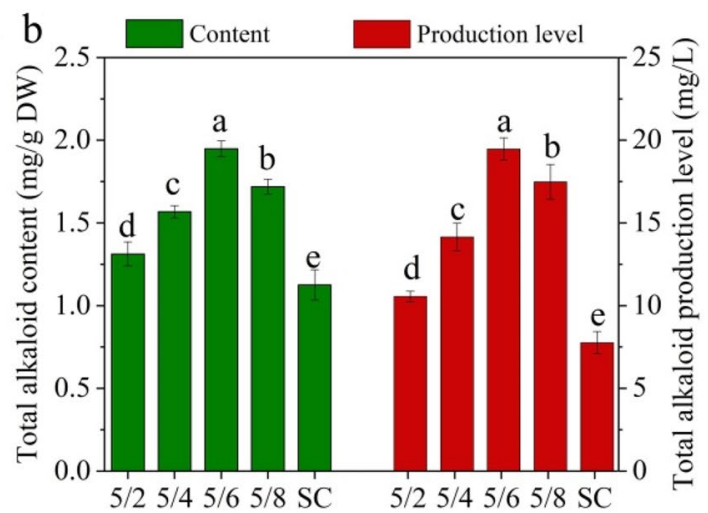

Immersion frequency

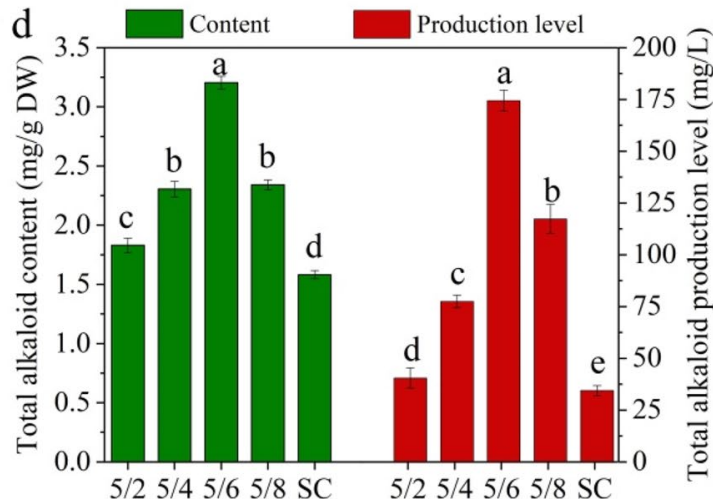

Immersion frequency

Fig. 3 Effect of immersion frequency on total alkaloid accumulation of D. nobile after a 20 days, b 40 days, $\mathbf{c} 60$ days and $\mathbf{d} 80$ days of culture. SC means semi-solid system culture as a control. Data represents the mean \pm standard error of three replicates. Bars followed by a different letter denote significant statistical differences (Tukey, $\mathrm{P} \leq 0.05$ )

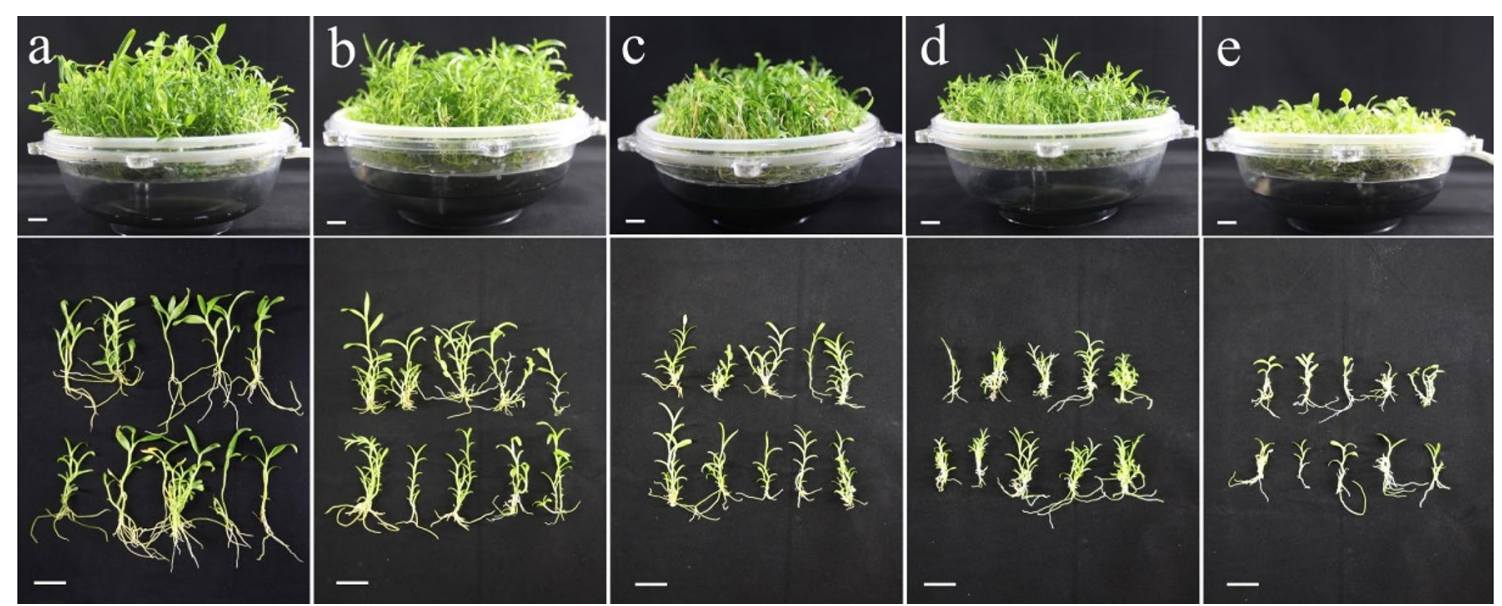

Fig. 4 Effect of MeJA concentrations (a $0 \mu \mathrm{M}, \mathbf{b} 5 \mu \mathrm{M}, \mathbf{c} 10 \mu \mathrm{M}, \mathbf{d} 15 \mu \mathrm{M}$ and e $20 \mu \mathrm{M})$ in TIBS medium on growth of D. nobile for 30 days of MeJA treatment. Scale $b a r=2 \mathrm{~cm}$ 


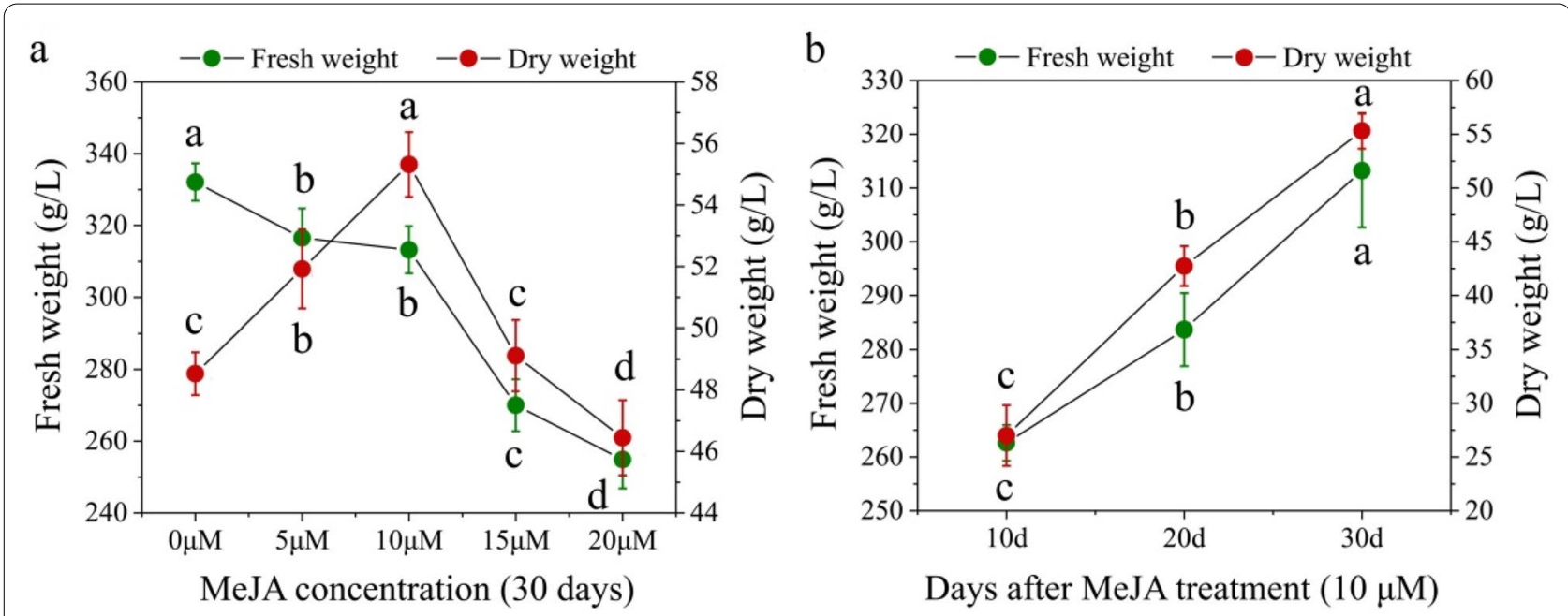

Fig. 5 a Effect of MeJA concentration on biomass accumulation of D. nobile after 30 days of MeJA treatment using TIBS culture. $\mathbf{b}$ Effect of culture time on biomass accumulation of D. nobile at a MeJA concentration of $10 \mu \mathrm{M}$ using TIBS culture. Data represents the mean \pm standard error of three replicates. Bars followed by a different letter denote significant statistical differences (Tukey, $\mathrm{P} \leq 0.05$ )
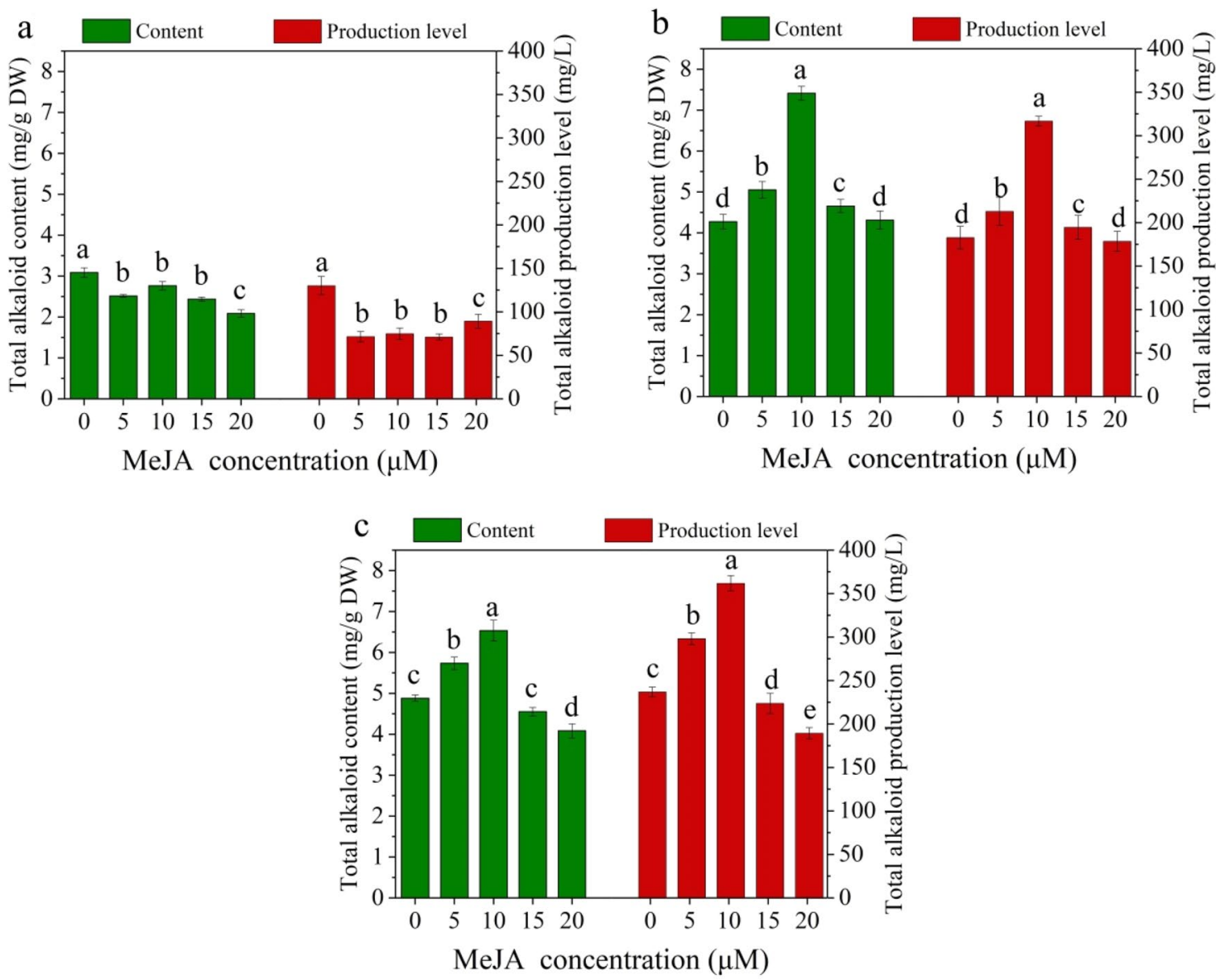

Fig. 6 Effect of MeJA concentration on total alkaloid accumulation of D. nobile after $\mathbf{a} 10$ days, $\mathbf{b} 20$ days and $\mathbf{c} 30$ days of MeJA treatment. Data represents the mean \pm standard error of three replicates. Bars followed by a different letter denote significant statistical differences (Tukey, $\mathrm{P} \leq 0.05$ ) 


\section{Comparison of SSS, TIBS, and TIBS-MeJA}

The biomass and total alkaloid content of in vitro seedlings grown under the three culture modes were compared to determine the most suitable scheme for the production of alkaloids by $D$. nobile. In all culture modes, the fresh medium was replaced after 50 days of culture, and the MeJA was added to the fresh medium in the type of TIBS combined with the MeJA system (TIBS-MeJA). Table 1 shows that the optimum total alkaloid content, fresh weight, and dry weight of $D$. nobile in different culture systems, and the TIBS cultured seedlings were all significantly higher than those in the traditional SSS culture. Specifically, TIBS-MeJA contained the maximum total alkaloid content $(7.41 \mathrm{mg} / \mathrm{g}$ DW) after 20 days of MeJA treatment, which was 2.32- and 4.69-fold higher than TIBS and SSS without MeJA after 80 days of culture. It can be calculated from Table 1 that the maximum total alkaloid production level $(361.24 \mathrm{mg} / \mathrm{L})$ appeared at TIBS-MeJA after 30 days of MeJA treatment was 2.07and 10.49-fold higher than TIBS and SSS, respectively. Therefore, we propose that the combination of TIBS and MeJA is an ideal method for the production of alkaloids from $D$. nobile plant tissue culture seedlings.

\section{Discussion}

To mimic natural plant growth conditions, TIBS is designed using a liquid medium to intermittently contact plant tissue to provide nutrition. This system provides an advantageous growth environment for plantlets in liquid culture, including easily absorbed nutrients and effective gas exchange, to ensure the healthy growth of seedlings [30, 31]. In this study, TIBS culture was more conducive to the accumulation of bioactive substances in $D$. nobile plantlets than SSS culture, was consistent with the results of Ashraf et al. [32] and Schumann et al. [33]. TIBS delivers an extremely aerobic environment for plant growth, as it provides forced ventilation through aeration. The immersion frequency is the most significant parameter for system productivity, which not only affects plant growth and micropropagation, but also affects the accumulation of bioactive compounds, especially medicinal plants [34-36]. The results of this study showed that lower immersion frequency (5/6 and 5/8) was beneficial to the accumulation of total alkaloid and biomass in plantlets, whereas higher immersion frequency $(5 / 2$ and 5/4) had the opposite effect (Fig. 3). These findings were consistent with those of Ivanov et al. [37] and Malik et al. [38]. The reason for this may be that the higher immersion frequency causes hyperhydricity and malformations of explants to reduce biomass and metabolites, since oxygen concentration in liquid media is often insufficient to meet the respiratory requirements of the submerged tissues [39].

MeJA treatment has significant effects on biomass and bioactive compounds accumulation during plant cell, tissue, and organ cultures [40-44]. Generally, MeJA induces the biosynthesis of alkaloid in plants of the Dendrobium genus by up-regulating the expression of alkaloid synthesis related genes $[27,45,46]$. However, the optimal concentration and treatment time of MeJA for maximum yield of active substances varied with the culture systems; for example, $100 \mu \mathrm{M}$ MeJA showed a maximum level of saponin content in cell suspension culture of Leucas aspera Spreng over a period of 18 days [47]. Treatment with $150 \mu \mathrm{M}$ MeJA for $72 \mathrm{~h}$ enhanced camptothecin production in tissue cultures of Ophiorrhiza mungos var. angustifolia [48], and treatment with $100 \mu \mathrm{M}$ MeJA for 7 days promoted the production of valerian acid in valerian hairy root cultures of Valeriana officinalis [49]. Therefore, it is necessary to screen the MeJA concentration and treatment time to obtain the maximum accumulation of bioactive compounds. In this study, we added different concentrations of MeJA to the TIBS liquid medium that cultured for $50 \mathrm{~d}$. Results showed that the maximum total alkaloid content of plantlets was obtained at $10 \mu \mathrm{M}$ MeJA after cultured for an additional 20 days. Thus, we can speculate that MeJA enhances the synthesis of alkaloids in in vitro propagated seedlings, as has been

Table 1 Comparison of optimum total alkaloids and biomass production of $D$. nobile in different culture systems

\begin{tabular}{lllll}
\hline Culture system & $\begin{array}{l}\text { Total alkaloid content } \\
\text { (mg/g DW) }\end{array}$ & Fresh weight (g/L) & Dry weight (g/L) & $\begin{array}{l}\text { Total } \\
\text { culture } \\
\text { time (d) }\end{array}$ \\
\hline SSS & $1.58 \pm 0.03 \mathrm{~d}$ & $185.02 \pm 6.75 \mathrm{~d}$ & $21.80 \pm 0.68 \mathrm{c}$ & 80 \\
TIBS & $3.20 \pm 0.05 \mathrm{c}$ & $349.23 \pm 11.63 \mathrm{a}$ & $54.48 \pm 3.69 \mathrm{a}$ & 80 \\
TIBS-MeJA & $7.41 \pm 0.17 \mathrm{a}$ & $283.68 \pm 6.76 \mathrm{c}$ & $42.73 \pm 0.85 \mathrm{~b}$ & 70 \\
& $6.53 \pm 0.26 \mathrm{~b}$ & $313.22 \pm 10.57 \mathrm{~b}$ & $55.32 \pm 1.65 \mathrm{a}$ & 80 \\
\hline
\end{tabular}

TIBS-MeJA means seedlings are cultured with MeJA using TIBS

The total culture time was the sum of tissue culture time and MeJA elicitation culture time

Values in each column followed by different letters are significantly different at $\mathrm{p} \leq 0.05$ as of Post Hoc Multiple Comparisons Test 
shown in previous studies [50, 51]. In this study, we also know that the fresh weight was significantly lower than the control group, even at the lowest MeJA concentration. Plant tissue culture systems have diminished fresh weight after MeJA treatment [52-54], because MeJA can inhibit plant growth by restricting the volume and number of leaf cells and inhibiting mitosis through special patterns. However, the heaviest dry weight appeared at $10 \mu \mathrm{M}$ MeJA, while the fresh weight was heaviest without MeJA, which may be because MeJA not only promoted the accumulation of the secondary metabolites [55], but also reduced the water content of explants by promoting senescence $[56,57]$.

D. nobile grows for a long time in nature, requiring growth periods of approximately three years; hence, the period of extraction of bioactive compounds from plants is very long [12]. To quickly obtain medicinal plant compounds, plant tissue culture technologies that can effectively shorten the growth cycle have been designed and adopted. For example, plant tissue culture for sustainable valorization of secondary metabolites of Bryophyllum sp. [58], and in vitro shoot culture of Rhododendron fortunei was used for the commercial production of raw materials for extracting bioactive phytochemicals [59]. Previous studies have reported that the use of bioreactor culture systems and MeJA induction could promote the accumulation of plant bioactive compounds [50, 51, $60,61]$. In the present study, we combined the bioreactor systems with MeJA to efficiently produce alkaloids from $D$. nobile tissue culture seedlings. The results show the TIBS-MeJA was more conducive to the synthesis of alkaloids and could effectively shorten the production cycle, thus reducing production costs. During the culture process of the TIBS, the gas exchange inside and outside of the container could be effectively carried out to ensure the demand for $\mathrm{CO}_{2}$ and $\mathrm{O}_{2}$ for photosynthesis and respiration [62,63]. Therefore, tissue culture seedlings grew healthily in TIBS, resulting in more accumulation of alkaloids precursor substances and improvement of the ability of plants to synthesize alkaloids. In addition, the liquid medium used in the TIBS led to the uniform distribution of MeJA as an inducer in the medium [64], which had the ability to continuously promote the synthesis of alkaloids.

\section{Conclusions}

TIBS can be applied to large-scale production of $D$. nobile, and total alkaloid accumulation can be improved by immersion frequency $5 / 6$. Moreover, treatment with MeJA had a high elicitation effect on bioactive compound accumulation in in vitro-cultured $D$. nobile seedlings, and $10 \mu \mathrm{M}$ MeJA for 20 days of treatment promoted the production of total alkaloid. Thus, we successfully used
TIBS-MeJA to obtain the highest total alkaloid content and production level.

\section{Materials and methods}

Plant materials and preparation

Dendrobium nobile seeds were collected from Yunnan Province, China and grown in a greenhouse at Nanjing Normal University. Mature capsules of $D$. nobile obtained through artificial pollination were surface sterilized using $75 \%$ alcohol and 10\% hydrogen peroxide. Then, the sterile seeds were plated on $1 \frac{1}{2}$ MS medium ( $\mathrm{pH} 6.0$ ), replenished with $25 \mathrm{~g} / \mathrm{L}$ sucrose, $80 \mathrm{~g} / \mathrm{L} \mathrm{CW}$ (coconut water), $0.5 \mathrm{mg} / \mathrm{L}$ NAA ( $\alpha$-naphthaleneacetic acid), and $7.2 \mathrm{~g} / \mathrm{L}$ agar. Seeds were cultured in a photoperiod of $10 \mathrm{~h}$ light $/ 14 \mathrm{~h}$ dark at $25 \pm 1{ }^{\circ} \mathrm{C}$ for 30 days after 5 days of dark culture, and plantlets (stem length: 2-3 cm) from the seeds were used as plant material for further experiments.

\section{TIBS and SSS culture of $D$. nobile}

TIBS was provided by Biofunction Co. Ltd. (Nanjing, China) with a $6.6 \mathrm{~L}$ culture tank, which included a controller, culture tank, connecting tube, and air filter $(0.22 \mu \mathrm{m})$ (Fig. 7). The liquid $1 / 2 \mathrm{MS}$ medium ( $\mathrm{pH}$ 6.0, 1 L) containing $25 \mathrm{~g} / \mathrm{L}$ sucrose, $0.5 \mathrm{mg} / \mathrm{L}$ NAA, and $80 \mathrm{~g} / \mathrm{L}$ $\mathrm{CW}$, and $300 \mathrm{D}$. nobile plantlets were placed in each container for all treatments. Four immersion frequencies $(5 / 2,5 / 4,5 / 6$, and $5 / 8)$ were compared for the biomass and alkaloid content of $D$. nobile seedlings in TIBS. Here, immersion frequencies indicate the time immersed in liquid culture and the interval; " $5 / 2$ " for example, indicates that the plants were immersed in liquid medium for 5 min every $2 \mathrm{~h}$.

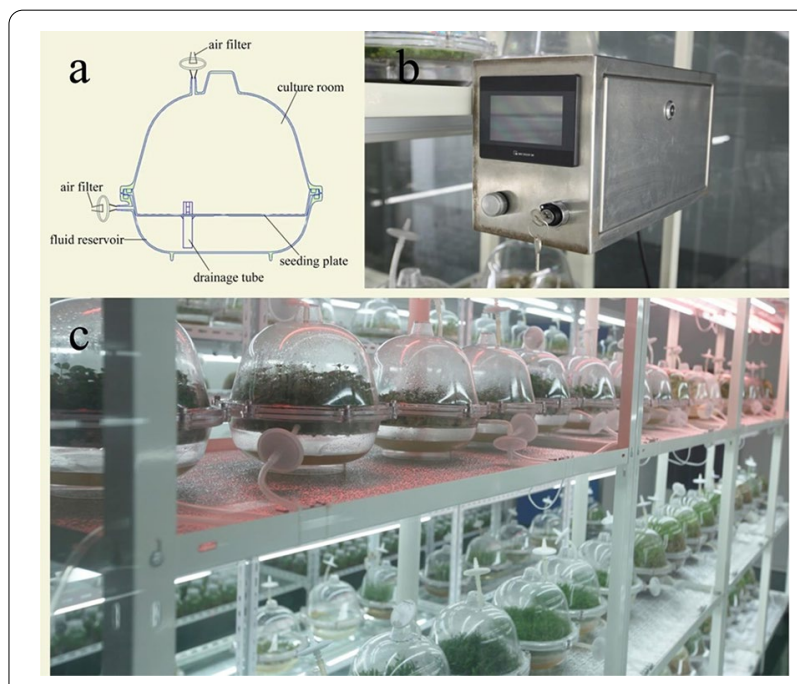

Fig. 7 a TIBS tank, b TIBS controller, c a typical culturing array 
In the SSS experiment, 300 explants were grown in 20 plantlet bottles (each bottle volume $0.5 \mathrm{~L}$ ) and each bottle contained $40 \mathrm{~mL}$ semi-solid medium. SSS medium was added to $7.2 \mathrm{~g} / \mathrm{L}$ agar as support. All cultures were maintained under a $10 \mathrm{~h}$ photoperiod under cool white light $(1800 \mathrm{l} \times)$ at $25 \pm 1{ }^{\circ} \mathrm{C}$ for 80 days.

\section{MeJA elicitation experiments}

MeJA (Sigma-Aldrich, 392,707) was dissolved in ethanol to prepare a stock solution and filter-sterilized through a $0.22 \mu \mathrm{m}$ nylon filter. When the plantlets were cultured in TIBS for 50 days, MeJA was added through aseptic replacement of liquid medium, and the immersion frequency was 5/6. MeJA was used as the elicitor at final concentrations of $5,10,15$, and $20 \mu \mathrm{M}(\mu \mathrm{mol} / \mathrm{L})$, and liquid medium without MeJA was used as control group. All TIBS cultures were maintained under cool white light $(1800 \mathrm{l} \times)$ at $25 \pm 1{ }^{\circ} \mathrm{C}$ for a $10 \mathrm{~h}$ photoperiod, and plantlets were harvested after 10,20, and 30 days of MeJA treatment to determine fresh weight, dry weight, and alkaloid accumulation.

\section{Determination of biomass and total alkaloid content}

The tissue culture seedlings of $D$. nobile were removed from the culture containers and washed with tap water. The fresh weight (FW, g/L), after the water on the plant surface was absorbed with absorbent paper, was obtained using an analytical balance. The dry weight (DW, g/L) was measured after the plant was dried in an oven at $60{ }^{\circ} \mathrm{C}$ for $36-48 \mathrm{~h}$ to absolute dryness. Dried plant $(0.5 \mathrm{~g})$ was ground into powder using a mortar, ammonia solution was added, and the mixture was allowed to stand for $0.5 \mathrm{~h}$. Following this, the mixed liquids were poured into a $50 \mathrm{~mL}$ flask, and $25 \mathrm{~mL}$ of chloroform was added for extraction. The chloroform in the flask was dried with a rotary evaporator after being maintained in a water bath at $70{ }^{\circ} \mathrm{C}$ for $2.5 \mathrm{~h}$, and then $5 \mathrm{~mL}$ of chloroform was poured into the flask to dissolve the dry residue, and then $2 \mathrm{~mL}$ of chloroform extract was aspirated and chloroform was added to the chloroform extract to $10 \mathrm{~mL}$. Potassium hydrogen phthalate buffer $(5 \mathrm{~mL}, \mathrm{pH} 4.5)$ and $2 \mathrm{~mL}$ of $0.04 \%(\mathrm{w} / \mathrm{v})$ bromocresol green solution were mixed and poured into the chloroform extract. The mixture was shaken vigorously for $3 \mathrm{~min}$ and allowed to stand for $0.5 \mathrm{~h}$, and then $1 \mathrm{~mL}$ alkaline alcohol $(0.01 \mathrm{~mol} / \mathrm{L}$ $\mathrm{NaOH}$ ) was added to $5 \mathrm{~mL}$ lower fractions for analysis. The absorbance value was determined using a spectrophotometer at $620 \mathrm{~nm}$, and then the total alkaloid content was calculated using a standard curve equation: $y=0.063 x+0.027,\left(R^{2}=0.996\right)(y$ and $x$ are the absorbance and content of dendrobine, respectively), which was obtained with dendrobine as the reference standard. The total alkaloid content and production level were calculated using the following formula: content $(\mathrm{mg} / \mathrm{g}$ $\mathrm{DW})=$ dendrobine $(\mathrm{mg}) \times 5 / 0.5 \mathrm{~g}$ and production level $(\mathrm{mg} / \mathrm{L})=\mathrm{DW}(\mathrm{g} / \mathrm{L}) \times$ content $(\mathrm{mg} / \mathrm{g} \mathrm{DW})[27,52]$.

\section{Acknowledgements}

The authors thank Ou Jiangtao and Hu Yanhua for their excellent technical assistance.

\section{Authors' contributions}

$\mathrm{BHZ}$ and $\mathrm{XYD}$ conceived and designed the study. $\mathrm{BHZ}, \mathrm{ZTN}$, and $\mathrm{CL}$ conducted the experiments. QYX and WL contributed to analytical tools. XJL and XYD analyzed the data and wrote the manuscript. All authors read and approved the final manuscript.

\section{Funding}

This work was supported by the financial support of the Jiangsu Agriculture Science and Technology Innovation Fund (No. CX(18)3063).

\section{Availability of data and materials}

The datasets used and/or analyzed during the current study are available from the corresponding authors upon reasonable request.

\section{Declarations}

Ethics approval and consent to participate Not applicable.

\section{Consent for publication}

Not applicable.

\section{Competing interests}

The authors declare that they have no competing interests.

Received: 18 May 2021 Accepted: 12 January 2022

Published online: 22 January 2022

\section{References}

1. Zhu SY, Niu ZT, Xue QY, Wang H, Xie XZ, Ding XY. Accurate authentication of Dendrobium officinale and its closely related species by comparative analysis of complete plastomes. Acta Pharm Sin B. 2018;8(6):969-80.

2. Cheng XF, Chen W, Zhou ZH, Liu JJ, Wang HZ. Functional characterization of a novel tropinone reductase-like gene in Dendrobium nobile Lindl. J Plant Physiol. 2013;170(10):958-64.

3. Wen ZZ, Lin Y, Liu YQ, Wang M, Wang YQ, Liu W. Effects of paclobutrazol in vitro on transplanting efficiency and root tip development of Dendrobium nobile. Biol Plant. 2013;57(3):576-80.

4. Bhattacharyya P, Kumaria S, Tandon P. High frequency regeneration protocol for Dendrobium nobile: a model tissue culture approach for propagation of medicinally important orchid species. S Afr J Bot. 2016;104:232-43.

5. Wang $Z H$, Wang $L, Y e Q S$. High frequency early flowering from in vitro seedlings of Dendrobium nobile. Sci Hortic. 2009;122(2):328-31.

6. Malabadi RB, Mulgund GS, Kallappa N. Micropropagation of Dendrobium nobile from shoot tip sections. J Plant Physiol. 2005;162(4):473-8.

7. Mou Z, Zhao Y, Ye F, Shi Y, Kennelly EJ, Chen S, Zhao D. Identification, biological activities and biosynthetic pathway of Dendrobium alkaloids. Front Pharmacol. 2021;12: 605994.

8. Nie J, Jiang LS, Zhang Y, Tian Y, Li LS, Lu YL, Yang WJ, Shi JS. Dendrobium nobile Lindl. alkaloids decreases the level of intracellular beta-amyloid by improving impaired autolysosomal proteolysis in APP/PS1 mice. Front Pharmacol. 2018;9:01479.

9. Huang $\mathrm{S}$, Wu Q, Liu H, Ling H, He YQ, Wang CH, Wang ZT, Lu YL, Lu YF. Alkaloids of Dendrobium nobile lindl. altered hepatic lipid homeostasis regulation of bile acids. J Ethnopharmacol. 2019;241: 111976.

10. Liu B, Huang B, Liu J, Shi JS. Dendrobium nobile Lindl alkaloid and metformin ameliorate cognitive dysfunction in senescence-accelerated mice 
via suppression of endoplasmic reticulum stress. Brain Res. 2020;1741: 146871.

11. Lv LL, Liu J, Li LS, Jin F, Xu YY, Wu Q, Liu J, Shi JS. Dendrobium nobile Lindl. alkaloids ameliorate cognitive dysfunction in senescence accelerated SAMP8 Mice by decreasing amyloid-beta aggregation and enhancing autophagy activity. J Alzheimer's Dis. 2020;76(2):657-69.

12. Teixeira da Silva JA, Ng TB. The medicinal and pharmaceutical importance of Dendrobium species. Appl Microbiol Biotechnol. 2017;101(6):2227-39.

13. Kunakhonnuruk B, Kongbangkerd A, Inthima P. Improving large-scale biomass and plumbagin production of Drosera communis A.St.-Hil. by temporary immersion system. Ind Crop Prod. 2019;137:197-202.

14. Kuo CL, Agrawal DC, Chang HC, Chiu YT, Huang CP, Chen YL, Huang SH, Tsay HS. In vitro culture and production of syringin and rutin in Saussurea involucrata (Kar. et Kir.) —an endangered medicinal plant. Bot Stud. 2015;56:8.

15. Malik S, Mirjalili MH, Fett-Neto AG, Mazzafera P, Bonfill M. Living between two worlds: two-phase culture systems for producing plant secondary metabolites. Crit Rev Biotechnol. 2013;33(1):1-22.

16. Swaraz AM, Sumi SK, Sultana F, Hasan M, Islam MM, Bari MW, Islam MA, Satter MA, Ahmed KS, Hossain MH. Bioactive compound and bioactivity fidelitous micropropagation method of Blumea lacera (Burm. F.) DC.: a large scale production potential. Ind Crop Prod. 2020;151: 112370.

17. Jang HR, Lee HJ, Shohael AM, Park BJ, Paek KY, Park SY. Production of biomass and bioactive compounds from shoot cultures of Rosa rugosa using a bioreactor culture system. Hortic Environ Biotechnol. 2016;57(1):79-87.

18. Kunakhonnuruk B, Inthima P, Kongbangkerd A. In vitro propagation of Rheophytic Orchid, Epipactis flava Seidenf - a comparison of semi-solid, continuous immersion and temporary immersion systems. Biology (Basel). 2019;8(4):8.

19. Ptak A, Moranska E, Skrzypek E, Warchol M, Spina R, Laurain-Mattar D, Simlat M. Carbohydrates stimulated Amaryllidaceae alkaloids biosynthesis in Leucojum aestivum L. plants cultured in RITA ${ }^{\circledR}$ bioreactor. PeerJ. 2020;8: e8688.

20. Szopa A, Kokotkiewicz A, Bednarz M, Jafernik K, Luczkiewicz M, Ekiert H. Bioreactor type affects the accumulation of phenolic acids and flavonoids in microshoot cultures of Schisandra chinensis (Turcz.) Baill. Plant Cell Tissue Organ Cult. 2019;139(1):199-206.

21. Ramirez-Mosqueda MA, Iglesias-Andreu LG, Ramirez-Madero G, Hernandez-Rincon EU. Micropropagation of Stevia rebaudiana Bert. in temporary immersion systems and evaluation of genetic fidelity. S Afr J Bot. 2016;106:238-43.

22. Baque MA, Moh SH, Lee EJ, Zhong JJ, Paek KY. Production of biomass and useful compounds from adventitious roots of high-value added medicinal plants using bioreactor. Biotechnol Adv. 2012;30(6):1255-67.

23. Akhgari A, Laakso I, Maaheimo H, Choi YH, Seppanen-Laakso T, OksmanCaldentey KM, Rischer H. Methyljasmonate elicitation increases terpenoid indole alkaloid accumulation in Rhazya stricta hairy root cultures. Plants (Basel). 2019;8(12):534.

24. Gao WJ, Meng QR, Luo H, Chen F, Zhou YW, He M. Transcriptional responses for biosynthesis of flavor volatiles in methyl jasmonate-treated Chrysanthemum indicum var. aromaticum leaves. Ind Crop Prod. 2020;147: 112254 .

25. Luo WY, Yang F, Piao XC, Jin MY, Tian W, Gao Y, Lian ML. Promising strategy to efficiently improve the kinsenoside and polysaccharide production of rhizome cultures of Anoectochilus roxburghii (Wall.) Lindl. Ind Crop Prod. 2018;125:269-75.

26. Commault AS, Fabris M, Kuzhiumparambil U, Adriaans J, Pernice M, Ralph PJ. Methyl jasmonate treatment affects the regulation of the 2-C-methylD-erythritol 4-phosphate pathway and early steps of the triterpenoid biosynthesis in Chlamydomonas reinhardtii. Algal Res. 2019;39: 101462.

27. Jiao CY, Song C, Zheng SY, Zhu YP, Jin Q, Cai YP, Lin Y. Metabolic profiling of Dendrobium officinale in response to precursors and methyl jasmonate. Int J Mol Sci. 2018;19(3):728.

28. Pei TL, Ma PD, Ding K, Liu SJ, Jia YY, Ru M, Dong JE, Liang ZS. SmJAZ8 acts as a core repressor regulating JA-induced biosynthesis of salvianolic acids and tanshinones in Salvia miltiorrhiza hairy roots. J Exp Bot. 2018;69(7):1663-78.

29. Yi S, Kuang T, Miao Y, Xu Y, Wang Z, Dong LB, Tan N. Discovery and characterization of four glycosyltransferases involved in anthraquinone glycoside biosynthesis in Rubia yunnanensis. Org Chem Front. 2020;7(17):2442-8.
30. Etienne H, Berthouly M. Temporary immersion systems in plant micropropagation. Plant Cell Tissue Organ Cult. 2002;69(3):215-31.

31. Isah T, Umar S, Mujib A, Sharma MP, Rajasekharan PE, Zafar N, Frukh A. Secondary metabolism of pharmaceuticals in the plant in vitro cultures: strategies, approaches, and limitations to achieving higher yield. Plant Cell, Tissue Organ Cult. 2018;132(2):239-65.

32. Ashraf MF, Abd Aziz M, Stanslas J, Kadir MA. Optimization of immersion frequency and medium substitution on microtuberization of Chlorophytum borivilianum in RITA system on production of saponins. Process Biochem. 2013;48(1):73-7.

33. Schumann A, Berkov S, Claus D, Gerth A, Bastida J, Codina C. Production of galanthamine by Leucojum aestivum shoots grown in different bioreactor systems. Appl Biochem Biotechnol. 2012;167(7):1907-20.

34. McAlister B, Finnie J, Watt MP, Blakeway F. Use of the temporary immersion bioreactor system (RITA ${ }^{\circledR}$ ) for production of commercial Eucalyptus clones in Mondi Forests (SA). Plant Cell Tissue Organ Cult. 2005;81(3):347-58.

35. Jesionek A, Kokotkiewicz A, Wlodarska P, Zabiegala B, Bucinski A, Luczkiewicz M. Bioreactor shoot cultures of Rhododendron tomentosum (Ledum palustre) for a large-scale production of bioactive volatile compounds. Plant Cell Tissue Organ Cult. 2017;131(1):51-64.

36. Ruta C, De Mastro G, Ancona S, Tagarelli A, De Cillis F, Benelli C, Lambardi M. Large-scale plant production of Lycium barbarum L. by liquid culture in temporary immersion system and possible application to the synthesis of bioactive substance. Plants (Basel). 2020;9(7):844.

37. Ivanov I, Georgiev V, Georgiev M, Ilieva M, Pavlov A. Galanthamine and related alkaloids production by Leucojum aestivum $\mathrm{L}$. shoot culture using a temporary immersion technology. Biochem Biotechnol. 2011;163(2):268-77.

38. Malik M, Warchol M, Pawlowska B. Liquid culture systems affect morphological and biochemical parameters during Rosa canina plantlets in vitro production. Not Bot Horti Agrobot Cluj Napoca. 2018:46(1):58-64.

39. Vidal N, Sanchez C. Use of bioreactor systems in the propagation of forest trees. Eng Life Sci. 2019;19(12):896-915.

40. Li C, Wang P, Menzies NW, Lombi E, Kopittke PM. Effects of methyl jasmonate on plant growth and leaf properties. J Plant Nutr Soil Sci. 2018;181(3):409-18.

41. See KS, Bhatt A, Keng CL. Effect of sucrose and methyl jasmonate on biomass and anthocyanin production in cell suspension culture of Melastoma malabathricum (Melastomaceae). Rev Biol Trop. 2011:59(2):597-606.

42. Zhao YX, Chen YC, Gao M, Yin HF, Wu LW, Wang YD. Overexpression of geranyl diphosphate synthase small subunit 1 (LCGPPS.SSU1) enhances the monoterpene content and biomass. Ind Crop Prod. 2020;143: 111269

43. Baenas N, Garcia-Viguera C, Moreno DA. Elicitation: a tool for enriching the bioactive composition of foods. Molecules. 2014:19(9):13541-63.

44. Hidalgo D, Sanchez R, Lalaleo L, Bonfill M, Corchete P, Palazon J. Biotechnological production of pharmaceuticals and biopharmaceuticals in plant cell and organ cultures. Curr Med Chem. 2018;25(30):3577-96.

45. Adejobi Ol, Guan J, Yang L, Hu JM, Yu A, Muraguri S, Liu A. Transcriptomic analyses shed light on critical genes associated with bibenzyl biosynthesis in Dendrobium officinale. Plants. 2021;10(4):633.

46. Fan HH, Wu QJ, Wang X, Wu L, Cai Y, Lin Y. Molecular cloning and expression of 1-deoxy-d-xylulose-5-phosphate synthase and 1-deoxy-d-xylulose-5-phosphate reductoisomerase in Dendrobium officinale. Plant Cell Tissue Organ Cult. 2016:125(2):381-5.

47. Vijendra PD, Jayanna SG, Kumar V, Sannabommaji T, Rajashekar J, Gajula H. Product enhancement of triterpenoid saponins in cell suspension cultures of Leucas aspera Spreng. Ind Crop Prod. 2020;156: 112857.

48. Krishnan JJ, Gangaprasad A, Satheeshkumar K. Exogenous methyl jasmonate acts as a signal transducer in the enhancement of camptothecin (CPT) production from in vitro cultures of Ophiorrhiza mungos L. var. angustifolia (Thw.) Hook. f. Ind Crop Prod. 2018;119:93-101.

49. Torkamani MRD, Jafari M, Abbaspour N, Heidary R, Safaie N. Enhanced production of valerenic acid in hairy root culture of Valeriana officinalis by elicitation. Cent Eur J Biol. 2014;9(9):853-63.

50. Paeizi M, Karimi F, Razavi K. Changes in medicinal alkaloids production and expression of related regulatory and biosynthetic genes in response to silver nitrate combined with methyl jasmonate in Catharanthus roseus in vitro propagated shoots. Plant Physiol Biochem. 2018;132:623-32. 
51. Zhou W, Shi M, Deng C, Lu S, Huang F, Wang Y, Kai G. The methyl jasmonate-responsive transcription factor SmMYB1 promotes phenolic acid biosynthesis in Salvia miltiorrhiza. Hortic Res. 2021;8(1):10.

52. Wang HQ, Jin MY, Paek KY, Piao XC, Lian ML. An efficient strategy for enhancement of bioactive compounds by protocorm-like body culture of Dendrobium candidum. Ind Crop Prod. 2016;84:121-30.

53. Yan Y, Stolz S, Chetelat A, Reymond P, Pagni M, Dubugnon L, Farmer EE. A downstream mediator in the growth repression limb of the jasmonate pathway. Plant Cell. 2007;19(8):2470-83.

54. Brioudes F, Joly C, Szécsi J, Varaud E, Leroux J, Bellvert F, Bertrand Cd, Bendahmane M. Jasmonate controls late development stages of petal growth in Arabidopsis thaliana. Plant J. 2009;60(6):1070-80.

55. Shi J, Ma CY, Qi DD, Lv HP, Yang T, Peng QH, Chen ZM, Lin Z. Transcriptional responses and flavor volatiles biosynthesis in methyl jasmonatetreated tea leaves. BMC Plant Biol. 2015;15:233.

56. Zhu XY, Chen JY, Xie ZK, Gao J, Ren GD, Gao S, Zhou X, Kuai B. Jasmonic acid promotes degreening via MYC2/3/4- and ANAC019/055/072mediated regulation of major chlorophyll catabolic genes. Plant J. 2015;84(3):597-610.

57. Zhang ZL, Xu MM, Guo YF. Ring/U-box protein AtUSR1 functions in promoting leaf senescence through ja signaling pathway in arabidopsis. Front Plant Sci. 2020;11:608589.

58. Garcia-Perez P, Lozano-Milo E, Landin M, Gallego PP. From ethnomedicine to plant biotechnology and machine learning: the valorization of the medicinal plant Bryophyllum sp. Pharmaceuticals. 2020;13(12):444.

59. Wei $X Y$, Chen JJ, Zhang CY, Wang ZH. In vitro shoot culture of Rhododendron fortunei: An important plant for bioactive phytochemicals. Ind Crop Prod. 2018;126:459-65.

60. Perez-Hernandez J, Nicasio-Torres MD, Sarmiento-Lopez LG, RodriguezMonroy M. Production of anti-inflammatory compounds in Sphaeralcea angustifolia cell suspension cultivated in stirred tank bioreactor. Eng Life Sci. 2019;19(3):196-205.

61. Sitarek P, Kowalczyk T, Picot L, Michalska-Hejduk D, Bijak M, Bialas AJ, Wielanek M, Sliwinski T, Skala E. Growth of Leonurus sibiricus L. roots with over-expression of AtPAP1 transcriptional factor in closed bioreactor, production of bioactive phenolic compounds and evaluation of their biological activity. Ind Crop Prod. 2018;122:732-9.

62. Escalona M, Samson G, Borroto C, Desjardins Y. Physiology of effects of temporary immersion bioreactors on micropropagated pineapple plantlets. In Vitro Cell Dev Biol Plant. 2003;39(6):651-6.

63. Aragón CE, Sánchez C, Gonzalez-Olmedo J, Escalona M, Carvalho L, Amâncio S. Comparison of plantain plantlets propagated in temporary immersion bioreactors and gelled medium during in vitro growth and acclimatization. Biol Plant. 2014;58(1):29-38.

64. Feito I, González A, Centeno ML, Fernández B, Rodríguez A. Transport and distribution of benzyladenine in Actinidia deliciosa explants cultured in liquid and solid media. Plant Physiol Biochem. 2001;39(10):909-16.

\section{Publisher's Note}

Springer Nature remains neutral with regard to jurisdictional claims in published maps and institutional affiliations.

Ready to submit your research? Choose BMC and benefit from:

- fast, convenient online submission

- thorough peer review by experienced researchers in your field

- rapid publication on acceptance

- support for research data, including large and complex data types

- gold Open Access which fosters wider collaboration and increased citations

- maximum visibility for your research: over $100 \mathrm{M}$ website views per year

At BMC, research is always in progress.

Learn more biomedcentral.com/submissions 